\title{
Non-ST elevation acute coronary syndromes; clinical landscape, management strategy and in-hospital outcomes: an age perspective
}

\author{
Zainab Atiyah Dakhil ${ }^{* *}$ and Hasan Ali Farhan² (B)
}

\begin{abstract}
Background: As the elderly represent a substantial proportion of medical care beneficiaries, and there is limited data about age disparity in emerging countries, this study sought to investigate the impact of age on the management in patients with non-ST elevation acute coronary syndromes (NSTE-ACS).

Results: Two hundred patients with NSTE-ACS enrolled prospectively, patients' data, pharmacotherapy, management strategy as well timing to catheterization were documented. Patients grouped into $\geq 65$ years versus $<65$ years; $32.5 \%$ were $\geq 65$-year-old. The older group presented as high GRACE risk (Global Registry of Acute Coronary Events) (67.7\% versus $15.6 \%)$. Elderly patients were less likely to be referred for catheterization compared with younger counterparts (55.4\% versus $76.3 \%, p=0.003$ ). Within low risk class patients, none of the elderly versus 9.33\% of younger patients were catheterized within $2 \mathrm{~h}$; in the same line, none of the elderly versus $16 \%$ of younger patients were catheterized within $24 \mathrm{~h}$. Alternatively, at high risk class, $6.81 \%$ of the elderly and none of the younger patients were catheterized within $2 \mathrm{~h}$. On the univariate analysis of variables to predict invasive strategy, presence of history of prior $I H D$, diabetes, absent in-hospital acute heart failure or atrial fibrillation/flutter, higher haemoglobin and lower creatinine levels predicted the use of invasive strategy, while on multivariate analysis, acute heart failure $(95 \% \mathrm{Cl}-0.38$ to $-0.41, p=0.01$ ), lower haemoglobin ( $95 \% \mathrm{Cl} 0.002-0.07, p=0.03$ ), and atrial fibrillation/flutter ( $95 \% \mathrm{Cl}-0.48$ to $-0.02, p=0.03$ ) predicted conservative strategy. The elderly were more likely to have acute heart failure $(32.3 \%$ versus $14.8 \%, p=0.004)$, same as stroke $(3.1 \%$ versus none, $p=0.04)$.
\end{abstract}

Conclusions: Less-invasive strategy used in the elderly with NSTE-ACS compared with younger counterparts, yet age was not a predictor of catheterization underuse on multivariate analysis. It is crucial to bridge the age gap in the healthcare system in setting of ACS management by grasping the attention of decision makers and emphasizing on the adherence of healthcare providers to the guidelines to improve cardiovascular care and outcomes.

Keywords: Quality of care, Age disparity, Healthcare equity, Audit, Elderly, GRACE score

\section{Background}

Healthcare disparities have recently raised the increasing amount of attention by researchers who suggested a wide range of inequity in the access to healthcare according to age, gender, socioeconomic status and

\footnotetext{
* Correspondence: stethoscope.med@gmail.com

${ }^{1}$ Al-Kindy College of Medicine, University of Baghdad, Baghdad, Iraq

Full list of author information is available at the end of the article
}

ethnicity [1, 2]. Despite elderly patients having the highest absolute risk reduction from intervention in the context of acute coronary syndromes (ACS), there are other predictors that might impact decision-making and outcomes like frailty, cognitive impairment, comorbidities and bleeding risk [3]; however, age alone should not deprive patients from invasive management strategy especially that risk assessment tools on which the 
management plan is largely based like GRACE and TIMI scores consider age in risk estimation [4]. Taking in consideration the high penetration of age disparity in practice along with that elderly patients are becoming an increasingly substantial proportion of medical care beneficiaries [5], it became necessary to assess the presence as well as predictors for such disparity that can result frequently in treatment-risk paradox which will impact remarkably cardiovascular outcomes. Little is known about age disparity in the management of non-ST elevation acute coronary syndromes (NSTE-ACS) in emerging countries; in response, this study sought to investigate the impact of age on pharmacotherapy prescription, decision and timing of intervention in patients with NSTE-ACS.

\section{Methods \\ Design}

This is a prospective multicentre study.

\section{Setting and duration}

The study was conducted in three teaching, percutaneous coronary intervention (PCI)-capable centres from January, 2018 to June, 2019; recruitment of cases was done sequentially during affiliation of the investigator to each cardiac centre.

\section{Patient selection}

The study included patients who were diagnosed as NSTE-ACS (patients with acute chest pain with no persistent ST elevation) [6]. Exclusion criteria were persistent ST elevation in ECG, new or presumed new LBBB, active malignancy, end-stage renal disease or endstage liver disease, recent history of upper GIT bleeding and patient refused invasive strategy.

\section{Data collection}

A detailed history was taken from each patient including demographic features and comorbidities; results of in-hospital investigations were documented including ECG, echocardiography, haemoglobin, blood urea, serum creatinine and serum troponin. GRACE risk score was calculated with subsequent categorization of each patient into low, intermediate and high risk class according to the GRACE scores as the following: $\leq 108,109-140$ and $>140$ respectively [4]. The patients were followed up during hospitalization with subsequent documentation of any of the following in-hospital complications: acute heart failure, recurrent or ongoing ischemic chest pain, cardiogenic shock, life-threatening arrhythmias, thromboembolic events (ischemic limb or pulmonary embolism), stroke and death.

\section{In-hospital management}

Drugs prescribed during hospitalization were recorded for each patient as well as whether patient had catheterization during index hospitalization or not. For patients who were treated invasively, timing to catheterization was calculated and recorded.

Patients were grouped into two categories: those with age < 65 years versus age $\geq 65$ years. The baseline characteristics, comorbidities, prescribed drugs, management strategy (conservative versus invasive), timing to intervention and in-hospital outcomes were compared between the two categories.

\section{Primary and secondary outcomes}

Primary outcome in this study was decision and timing of invasive strategy in patients according to their risk class. Secondary outcome was encountering any of the forementioned in-hospital complications.

\section{Coronary angiographic profile and revascularization recommendation}

For patients who were catheterized during hospitalization, the results of coronary angiography were recorded; coronary lesions were classified into [7]

1. Patient with normal coronary arteries

2. Patients with non-critical coronary artery lesion(s): lesions causing $<70 \%$ of luminal narrowing

3. Patient with critical coronary artery lesion(s): lesions causing $\geq 70 \%$ luminal narrowing

If coronary revascularization (PCI versus coronary artery bypass graft $(\mathrm{CABG})$ ) was recommended by the treating team, then it was documented for each patient.

\section{Ethical approval}

The study was performed in accordance with the declaration of Helsinki and approved by local ethical and scientific committee. Informed consent was obtained from all the participants.

\section{Statistical analysis}

Collected data were coded and input into the computer using SPSS version 24. Numerical variables were expressed as mean \pm standard deviation; categorical variables were expressed as percentages. Statistical analysis of numerical variables was done by $t$ test, while that of categorical variables was done by chi-squared test to compare frequency ratios between categories. Multiple regression analysis model was structured to study the independent predictors of using invasive strategy. $p$ value $<0.05$ is considered statistically significant. 


\section{Results}

\section{Cohort baseline characteristics}

A total of 200 patients were enrolled, of whom $32.5 \%$ were $\geq 65$ years old; mean age of the older group was $71.82 \pm 6.03$ years compared with $52.46 \pm 8.09$ years in the younger group ( $p<0.0001) ; 44.6 \%$ of the patients were females in the older group versus $22.2 \%$ in younger patients $(p=0.001)$. Hypertension (HT) and diabetes (DM) were more evident in the older group (84.6 and $61.5 \%$ respectively), while younger patients were more smokers (42.2\% versus $18.5 \%)$. Elderly patients were more likely to be presented with dyspnoea (38.5\% versus $25.2 \%)(p=0.054)$, and they were presented as high GRACE risk class (67.7\% versus $15.6 \%$ ), while younger counterparts were presented more as low GRACE risk class $(55.6 \%$ versus $13.8 \%) p<0.0001$. Elderly patients had higher blood urea $(47.2 \pm 20.6$ versus $35.6 \pm 15.05$, $p<0.0001)$ and higher serum creatinine $(1.04 \pm 0.3$ versus $0.9 \pm 0.3, p=0.01)$, while they had lower haemoglobin than their younger counterparts $(12.7 \pm 1.9$ versus $13.7 \pm 2.06, p=0.006)$; these results can be seen in Table 1.

\section{In-hospital management \\ Pharmacotherapy}

Both groups were treated at the same rate with aspirin 98.5\%, while P2Y12 inhibitors were used in all elderly $100 \%$ and most younger patients 99.3\%; heparin was used less in the elderly, same as B-blockers, ACEI/ARBs and statins; however, there is no statistical difference between two groups regarding pharmacotherapy during hospitalization apart from mineralocorticoid receptor antagonist (MRA) which was used in the elderly in $18.5 \%$ versus $6.7 \%$ in younger counterparts $(p=0.01)$; these results are shown in Table 2 .

\section{Coronary catheterization and timing to intervention}

Elderly patients were less likely to be referred for catheterization compared with the younger counterparts (55.4\% versus $76.3 \%, p=0.003$ ); as seen in Fig. 1, within each age category, when considering GRACE risk class, the highest non-catheterization rate was seen in high risk class in both elderly and younger patients $(47.72 \%$ and $52.38 \%$ ) respectively. Regarding timing to intervention in view of each risk class, within the low-risk-class patients, none of the elderly versus $9.33 \%$ of the younger patients were catheterized within $2 \mathrm{~h}$; in the same line, none of the elderly versus $16 \%$ of the younger patients were catheterized within $24 \mathrm{~h}$. Alternatively, at high risk class, $6.81 \%$ of the elderly and none of the younger patients were catheterized within $2 \mathrm{~h}$, while $22.72 \%$ of the older patients and $32.8 \%$ of the younger patients were catheterized within more than $72 \mathrm{~h}$, as illustrated in Fig. 2. On univariate analysis of variables to predict invasive strategy, presence of history of prior IHD, diabetes, absent in-hospital acute heart failure or atrial fibrillation/flutter, higher haemoglobin and lower creatinine levels predicted the use of invasive strategy, while on multivariate analysis, acute heart failure (95\% CI -0.38 to $-0.41, p=0.01$ ), lower haemoglobin (95\% CI $0.002-0.07, p=0.03)$ and atrial fibrillation/flutter (95\% CI -0.48 to $-0.02, p=0.03$ ) predicted conservative strategy. The elderly were more likely to have acute heart failure $(32.3 \%$ versus $14.8 \%, p=0.004)$, same as stroke (3.1\% versus none, $p=0.04)$. See Tables 3 and 4 .

\section{Coronary angiographic findings and recommended revascularization mode}

Among patients who were referred for catheterization, critical coronary lesions were recorded more in the elderly group $(85.71 \%$ versus $72.27 \%)$, while normal coronary angiography was evident more in the younger group $(22.77 \%$ versus $8.57 \%)$; however, there were no statistically significant differences between the two groups regarding coronary findings nor revascularization recommendation (PCI versus $\mathrm{CABG}$ ); these findings are shown in Fig. 3.

\section{In-hospital complications and outcomes}

Older patients were more likely to have acute heart failure (AHF) than younger counterparts $(32.3 \%$ versus $14.8 \%, p=0.004)$, same as stroke $(3.1 \%$ in elderly and none in younger counterparts, $p=0.04$ ), while younger patients tend to develop life-threatening arrhythmias (6.7\% versus $1.5 \%, \mathrm{p}=0.1$ ) more. Atrial fibrillation (AF) and premature ventricular contractions (PVC) were most common arrhythmias in older patients (12.3 and $7.7 \%$ respectively). In-hospital death occurred more in older patients $(4.6 \%$ versus $1.5 \%, p=0.1)$; these findings are revealed in Figs. 4 and 5.

\section{Duration of hospitalization}

At the low risk class, elderly patients and younger patients were more likely to be hospitalized for 4-7 days in 70 and $53.33 \%$ respectively; at the high risk class, the older group was hospitalized more for $\leq 3$ days (46.42\%), while younger counterparts were hospitalized more for 4-7 days (52.38\%), as shown in Fig. 6.

\section{Discussion}

Despite the limited data about adherence of cardiologists to international guidelines in Iraq, it is only recently that healthcare disparities' impact on decision-making have been addressed [8, 9]; this called us for conducting further studies that cast a light on healthcare disparities including age disparity and its predictors [10] to inform stakeholders, hoping to respond by establishing quality improvement projects to bridge disparity gaps in 
Table 1 Baseline characteristics in patients with NSTE-ACS according to age category

\begin{tabular}{|c|c|c|c|}
\hline \multirow[t]{2}{*}{ Baseline characteristics } & $<65$ Years & $\geq 65$ Years & $p$ value \\
\hline & \multicolumn{2}{|l|}{$N(\%)$} & \\
\hline$N(\%)$ & $135(67.5 \%)$ & 65 (32.5\%) & - \\
\hline Age (mean $\pm S D$ ) years & $52.46 \pm 8.09$ & $71.82 \pm 6.03$ & $<0.0001$ \\
\hline Female gender & 30 (22.2\%) & $29(44.6 \%)$ & 0.001 \\
\hline Hypertension & $84(62.2 \%)$ & $55(84.6 \%)$ & 0.001 \\
\hline Diabetes & $58(43 \%)$ & $40(61.5 \%)$ & 0.014 \\
\hline $\mathrm{IHD}$ & $57(42.2 \%)$ & $39(60 \%)$ & 0.018 \\
\hline Family history & $44(32.6 \%)$ & $21(32.3 \%)$ & 0.9 \\
\hline Smoking & $57(42.2 \%)$ & $12(18.5 \%)$ & 0.001 \\
\hline Hyperlipidaemia & $26(19.3 \%)$ & 19 (29.2\%) & 0.1 \\
\hline Stroke & $3(2.2 \%)$ & $3(4.6 \%)$ & 0.3 \\
\hline Atrial fibrillation (new or old) & $9(6.7 \%)$ & $8(12.3 \%)$ & 0.1 \\
\hline Prior catheterization & $9(6.7 \%)$ & $8(12.3 \%)$ & 0.18 \\
\hline Prior PCl & $14(21.5 \%)$ & $21(15.6 \%)$ & 0.29 \\
\hline Prior CABG & $1(0.7 \%)$ & $4(6.2 \%)$ & 0.02 \\
\hline Dyspnoea & $34(25.2 \%)$ & 25 (38.5\%) & 0.054 \\
\hline Positive troponin & $57(42.2 \%)$ & $36(55.4 \%)$ & 0.08 \\
\hline Pulse rate (mean $\pm \mathrm{SD}$ ) BPM & $84.3 \pm 21.5$ & $85.8 \pm 22.3$ & 0.6 \\
\hline $\mathrm{SBP}($ mean $\pm \mathrm{SD}) \mathrm{mmHg}$ & $135.3 \pm 24.3$ & $139 \pm 27.4$ & 0.3 \\
\hline $\mathrm{DBP}($ mean $\pm \mathrm{SD}) \mathrm{mmHg}$ & $82.2 \pm 13.2$ & $79.03 \pm 11.7$ & 0.09 \\
\hline Ejection fraction & $54.8 \pm 11.6$ & $51.6 \pm 11.9$ & 0.1 \\
\hline Blood sugar & $182.6 \pm 110.1$ & $197.08 \pm 109.9$ & 0.4 \\
\hline Urea (mean $\pm \mathrm{SD}) \mathrm{mg} / \mathrm{dL}$ & $35.6 \pm 15.05$ & $47.2 \pm 20.6$ & $<0.0001$ \\
\hline Creatinine (mean $\pm \mathrm{SD}$ ) Mg/dL & $0.9 \pm 0.3$ & $1.04 \pm 0.3$ & 0.01 \\
\hline Estimated GFR (mean $\pm \mathrm{SD}$ ) $\mathrm{ml} / \mathrm{min} / 1.73 \mathrm{~m}^{2}$ & $90.75 \pm 20.11$ & $67.4 \pm 20.13$ & $<0.0001$ \\
\hline Haemoglobin (mean \pm SD) gm/L & $13.7 \pm 2.06$ & $12.7 \pm 1.9$ & 0.006 \\
\hline $\mathrm{WBC}($ mean $\pm \mathrm{SD}) \times 10^{3} / \mathrm{mcL}$ & $9.369 \pm 3.027$ & $9.362 \pm 2.859$ & 0.9 \\
\hline Platelets count (mean $\pm \mathrm{SD}$ )/mcL & $235020 \pm 77.075$ & $236250 \pm 76.375$ & 0.9 \\
\hline Hospitalization duration (mean \pm SD) days & $4.9 \pm 2.7$ & $4.8 \pm 2.8$ & 0.7 \\
\hline \multicolumn{4}{|l|}{ GRACE risk class } \\
\hline Low & 75 (55.6\%) & $9(13.8 \%)$ & \multirow[t]{3}{*}{$<0.0001$} \\
\hline Intermediate & 39 (28.9\%) & $12(18.5 \%)$ & \\
\hline High & $21(15.6 \%)$ & $44(67.7 \%)$ & \\
\hline
\end{tabular}

${ }^{\mathrm{a} G F R}$ estimated by CKD-EPI creatinine equation

practice. In response, the current study came to bring into view the underutilization of invasive strategy in elderly patients with NSTE-ACS, yet, it contradicted prior researches that suggested underuse of invasive strategy in elderly patients with high GRACE risk class despite most prognostic benefit [11] as current study revealed more conservative treatment in higher-risk patients in all patients in general and the younger age group in particular; the study contributes also by giving insight to timing of intervention and duration of hospitalization within the age categories according to GRACE risk class, an issue about which we have limited data.

Elderly patients are under-represented in clinical trials resulting in uncertainty of clinicians about impact and benefit of many therapeutic options in this population $[12,13]$ leading to under-prescription of guidelinedirected medical therapy (GDMT) in the setting of ACS; among factors that contribute to this under-prescription is the age-related pathophysiological changes resulting in altering pharmacokinetic and pharmacodynamic responses 
Table 2 Pharmacotherapy profile in patients with NSTE-ACS according to age category

\begin{tabular}{llll}
\hline Medication & $<65$ Years & $\geq 65$ Years & $\boldsymbol{p}$ value \\
& $\boldsymbol{N}(\%)$ & & \\
\hline Aspirin $^{\text {a }}$ & $133(98.5 \%)$ & $68(98.5 \%)$ & 0.9 \\
P2Y12 inhibitor & $134(99.3 \%)$ & $65(100 \%)$ & 0.4 \\
Heparin & $97(71.9 \%)$ & $46(70.8 \%)$ & 0.8 \\
B-blockers & $105(77.8 \%)$ & $49(75.4 \%)$ & 0.7 \\
Nitrate & $80(59.3 \%)$ & $42(64.6 \%)$ & 0.4 \\
Calcium channel blockers & $11(8.1 \%)$ & $10(15.4 \%)$ & 0.1 \\
ACEl/ARBs & $57(42.2 \%)$ & $27(41.5 \%)$ & 0.9 \\
Statin & $123(91.1 \%)$ & $53(81.5 \%)$ & 0.051 \\
Mineralocorticoid receptor & $9(6.7 \%)$ & $12(18.5 \%)$ & 0.01 \\
antagonist & & & \\
Loop diuretics & $21(15.6 \%)$ & $16(24.6 \%)$ & 0.1 \\
\hline
\end{tabular}

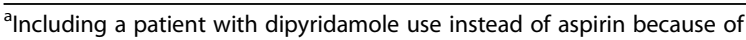
history of aspirin allergy

to drugs, the low weight that commonly occurs in elderly, increased bleeding events with use of antithrombotic and antiplatelet therapies, commonly associated anaemia and other comorbidities, and polypharmacy with subsequent drugs interaction [14-17]. However, current study showed more universal use of aspirin and P2Y12 inhibitors in both age groups compared with prior studies [12, 13, 18]. Despite guideline recommendations [19-21] and prognostic benefit, there is a trend to use statin more in the younger group, consistent with earlier studies $[12,18]$. While aging did not impact their prescription, Bblockers and ACEI/ARBs were used at a lower rate in the current study compared with earlier researches [12, 13]; B-blockers and ACEI/ARBs were expected to be used more significantly compared with the younger group in our study as the recruited elderly patients had more indications to use ACEI/ARBs in terms of being more diabetic, hypertensive with higher systolic blood pressure, have lower ejection fraction and remarkably developed heart failure during hospitalization more than their younger counterparts, yet the older study group had higher renal indices which might explain the relative under-prescription of ACEI/ARBs fearing from developing hyperkalaemia, in addition to potential complications of postural hypotension and increased risk of falls; however, such adverse effects can be overcome by proper monitoring of renal function and gradual up titration of doses $[15,22]$. In the same line, fearing from adverse effects of B-blockers like fatigue, dizziness, or physicians' perception of less efficacy in the elderly due to decrease B-receptors [13, 23], all can lead to under use of B-blockers in the older group in spite of their better prognostic effect in the elderly compared with younger counterparts in terms of reducing death and recurrent myocardial infarction [19-21]. Impaired left ventricular function and higher incidence of acute heart failure justify the higher rate of using loop diuretic and mineralocorticoid receptor antagonist in the older group. Older patients were less treated invasively; these results were supported by prior studies including GRACE and ROSAI-2 registries [13, 24-27]. Many factors contribute to less referral for catheterization in older patients with NSTE-ACS like associated comorbidities, especially anaemia and CKD, higher rate of bleeding complications and the more presentation with haemodynamic instability in this population [13]. Furthermore, there are contradictory results with respect to prognostic benefit of routine invasive strategy in the elderly with NSTE-ACS, MOSCA and Italian Elderly ACS trials [28, 29], which are two randomized controlled trials that showed no difference between invasive and conservative strategies in the elderly with NSTE-ACS in terms of recurrent MI, cardiovascular rehospitalization and mortality. However, After-Eighty

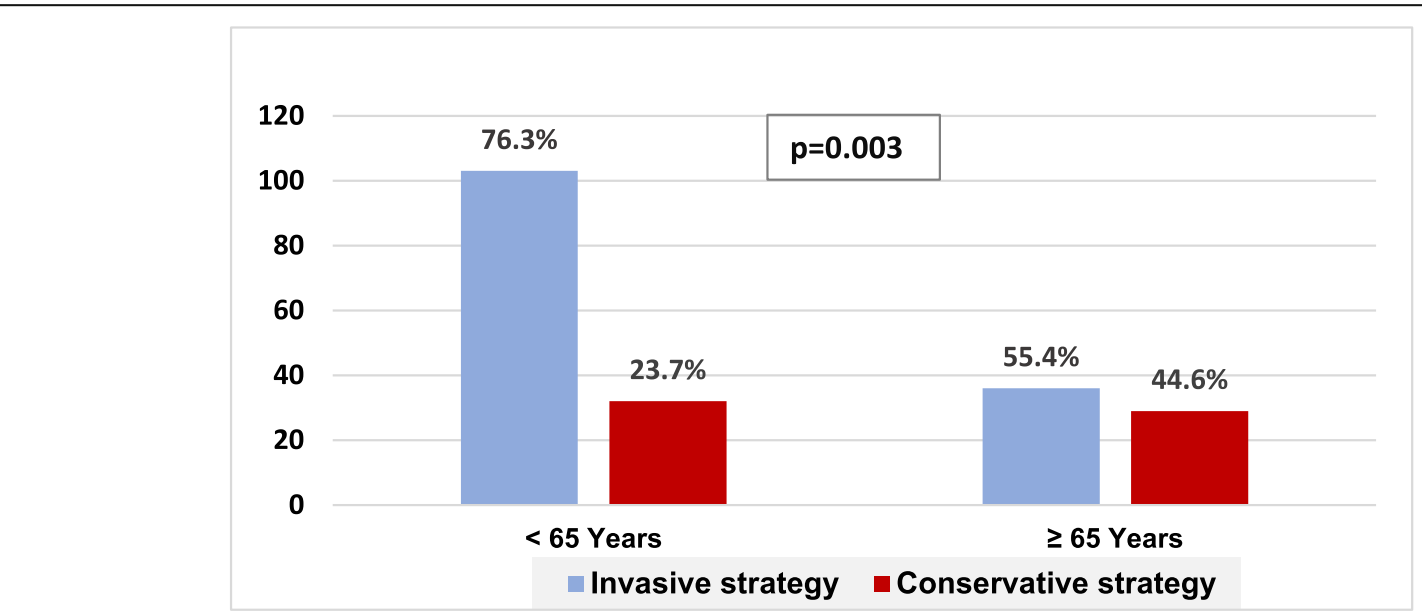

Fig. 1 Management strategy in NSTE-ACS according to age category 


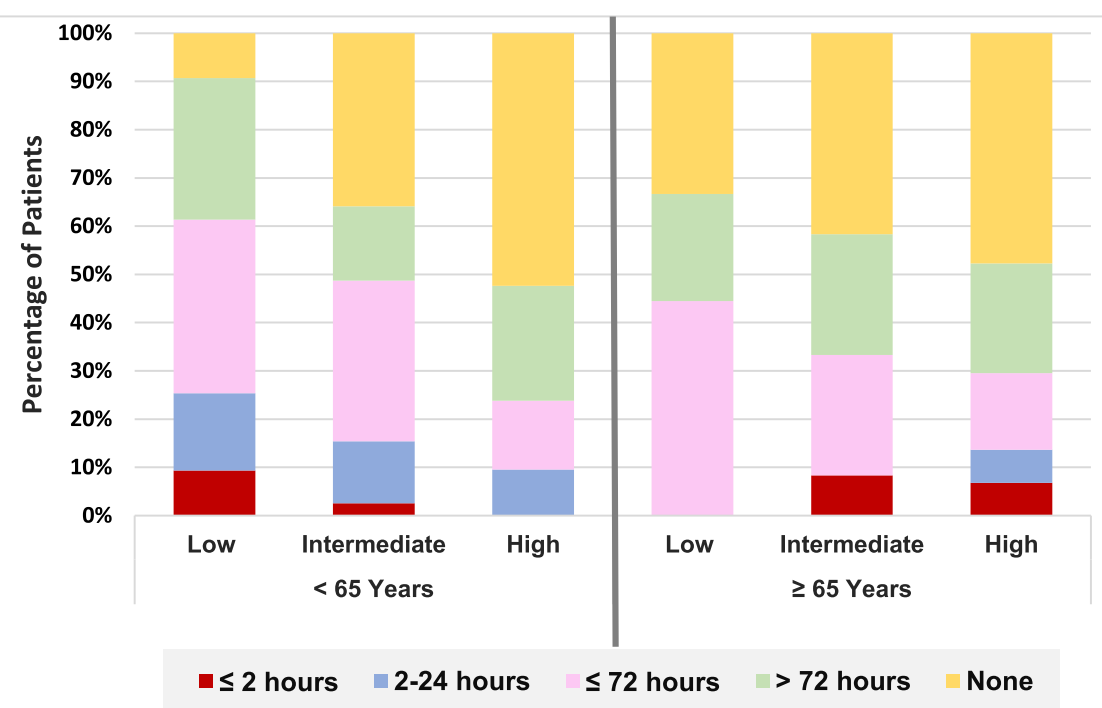

Fig. 2 Timing to catheterization in NSTE-ACS according to age and GRACE risk class. Comparing timing to catheterization between the two age categories according to risk class $p$ value $=0.4$ (low-risk class), 0.3 (intermediate-risk class) and 0.6 (high risk class)

trial, TACTICS-TIMI18 trial $[30,31]$ and other metaanalyses [32, 33] revealed decrease in recurrent MI, need for revascularization and death in elderly patients who were treated with early invasive strategy. Other metaanalysis showed less need for revascularization in the invasive strategy with no significant difference in all-cause mortality, cardiovascular mortality, stroke and MI [34]. GRACE registry also revealed mortality benefit of invasive strategy at 6 months follow-up but with no difference in MI rate [26]. Similarly, a real-life cohort study revealed lower in-hospital complications (AF, HF, stroke and death) same as lower long-term mortality with invasive strategy, while having no change regarding in-hospital cardiogenic shock, AV block and VT/VF, yet invasive strategy was associated remarkably with higher bleeding complications [35]. What can be abstracted from earlier studies is that it is not only chronological age that should determine the decision of intervention but also other factors like frailty, comorbidity, functional status and life expectancy.

Current study compared timing to catheterization between both age categories according to their GRACE risk class, despite that patients at low and intermediate GRACE risk classes were more to be catheterized in the younger age group, while at high GRACE risk class, the elderly were catheterized more and at earlier timing than their younger counterparts; however, the rate of use of early invasive strategy in high GRACE risk class in total is much lower than reported in literature [36] despite

Table 3 Univariate analysis of predictors of invasive strategy in NSTE-ACS

\begin{tabular}{llll}
\hline Variable & Conservative strategy & Invasive strategy & $\boldsymbol{p}$ value \\
\hline Age $\geq 65$ years & $29(44.6 \%)$ & $36(55.4 \%)$ & 0.003 \\
Female gender & $22(37.3 \%)$ & $37(62.7 \%)$ & 0.17 \\
IHD & $38(39.6 \%)$ & $58(60.4 \%)$ & 0.007 \\
Diabetes & $38(38.8 \%)$ & $60(61.2 \%)$ & 0.013 \\
Smoking & $16(23.2 \%)$ & $53(76.8 \%)$ & 0.103 \\
Positive troponin & $30(32.3 \%)$ & $63(67.7 \%)$ & 0.61 \\
Acute heart failure & $24(58.5 \%)$ & $17(41.5 \%)$ & $<0.0001$ \\
Cardiogenic shock & $4(66.7 \%)$ & $2(33.3 \%)$ & 0.051 \\
Ongoing chest pain & $18(36.7 \%)$ & $31(63.3 \%)$ & 0.27 \\
AF/A FL & $11(64.7 \%)$ & $6(35.3 \%)$ & 0.001 \\
Arrhythmias & $3(30 \%)$ & $7(70 \%)$ & 0.97 \\
Haemoglobin & $12.79 \pm 2.37$ & $13.64 \pm 1.87$ & 0.014 \\
Creatinine & $1.03 \pm 0.43$ & $0.92 \pm 0.24$ & 0.03 \\
\hline
\end{tabular}

aife-threatening arrhythmias 
Table 4 Multi-regression analysis of predictors of invasive strategy in NSTE-ACS ${ }^{*}$

\begin{tabular}{|c|c|c|c|c|c|}
\hline \multirow[t]{2}{*}{ Predictors } & \multirow{2}{*}{$\begin{array}{l}\text { Standard } \\
\text { error }\end{array}$} & \multirow{2}{*}{$\begin{array}{l}\text { Standardized } \\
\text { coefficient } \\
\text { (beta) }\end{array}$} & \multicolumn{2}{|c|}{ 95\% confidence interval } & \multirow[t]{2}{*}{$p$ value } \\
\hline & & & Lower & Upper & \\
\hline Age $\geq 65$ years & 0.07 & -0.101 & -0.25 & 0.05 & 0.2 \\
\hline Female gender & 0.08 & 0.05 & -0.11 & 0.22 & 0.52 \\
\hline $\mathrm{IHD}$ & 0.06 & -1 & -0.22 & 0.04 & 0.19 \\
\hline Diabetes & 0.07 & -0.07 & -0.20 & 0.07 & 0.33 \\
\hline Smoking & 0.07 & 0.05 & -0.09 & 0.2 & 0.48 \\
\hline Positive troponin & 0.06 & -0.001 & -0.13 & 0.13 & 0.99 \\
\hline Acute heart failure & 0.09 & -0.2 & -0.38 & -0.41 & 0.01 \\
\hline Cardiogenic shock & 0.2 & -0.12 & -0.73 & 0.06 & 0.09 \\
\hline Ongoing chest pain & 0.08 & 0.02 & -0.14 & 0.18 & 0.78 \\
\hline AF/A FL & 0.11 & -0.16 & -0.48 & -0.02 & 0.03 \\
\hline Arrhythmias $^{a}$ & 0.15 & -0.003 & -0.31 & 0.306 & 0.97 \\
\hline Haemoglobin & 0.01 & 0.17 & 0.002 & 0.07 & 0.03 \\
\hline Creatinine & 0.11 & -0.05 & -0.308 & 0.14 & 0.46 \\
\hline
\end{tabular}

aLife-threatening arrhythmias

${ }^{*} p$ value of the multiple regression model is $<0.0001$

the better prognostic benefit with early invasive strategy (within 24 h) in high-risk NSTE-ACS in terms of lower death, MI, and stroke as suggested by TIMACS trial [37] and ACUITY trial [38].

Current study showed that there are higher rates of critical coronary lesions in the elderly and higher rates of normal coronary angiography in the younger counterparts, while older patients were referred for CABG more than the younger group indicating higher-risk coronary anatomy in the elderly (left main stem or three-vessel disease). Prior researchers also showed higher normal coronary angiography in younger ACS patients as well as higher-risk coronary anatomy with increasing age, yet there is lower referral for PCI or CABG in older patients [39].

The study disclosed a higher rate of in-hospital complications in elderly patients in terms of acute heart failure and stroke. Interestingly, life-threatening arrhythmias were reported more in the younger group, while AF and multifocal PVC occurred more in the older counterparts; these results were supported by prior researchers [40] as higher rate of arrhythmias, HF, cardiogenic shock and death were recorded in older patients, while other researchers reported higher HF, recurrent MI and lifethreatening arrhythmias in younger patients in the time that $\mathrm{AF}$, cardiogenic shock and stroke recorded more in



Fig. 3 Coronary angiography findings and revascularization recommendation in NSTE-ACS according to age category. Among total patients referred for catheterization $(n=139)$, catheterization records were missed in 3 patients ( 1 in age $<65$ years and 2 in older counterparts) 




Fig. 4 Distribution of arrhythmias in NSTE-ACS according to age category. Patients who had more than one type of arrhythmia recorded within each type separately

the older group; however, these changes did not reach statistical significance [41]. The current study showed no significant difference in average duration of hospitalization according to age categories nor duration of hospitalization between the two age groups according to the GRACE risk class; results are consistent with prior researchers [42] and contradicted others [43]. The ESC guideline recommended discharging patients with NSTE-ACS within 48$72 \mathrm{~h}$ for patients at low risk class [44], while the current study revealed that the highest rate of patients among all GRACE risk classes in the younger group and low GRACE risk class in the older age were hospitalized for 4-7 days, while high-GRACE risk patients of the older age group were more likely to be hospitalized for $\leq 3$ days; this short period in high-GRACE risk elderly might be due to more use of invasive strategy in them compared to highGRACE risk younger counterparts. Despite prior studies, observed variables like lower comorbidities, higher use of ACEI/ARBs, lower use of loop diuretics and MRA, and higher left ventricular EF in those with shorter duration of hospitalization [42, 43], such factors were significantly different between the two age groups in our study, yet it seems that they did not signify duration of hospitalization, hence no significant difference between the two age categories. Earlier discharge of NSTE-ACS patients particularly those of low- and intermediate-GRACE risk classes is

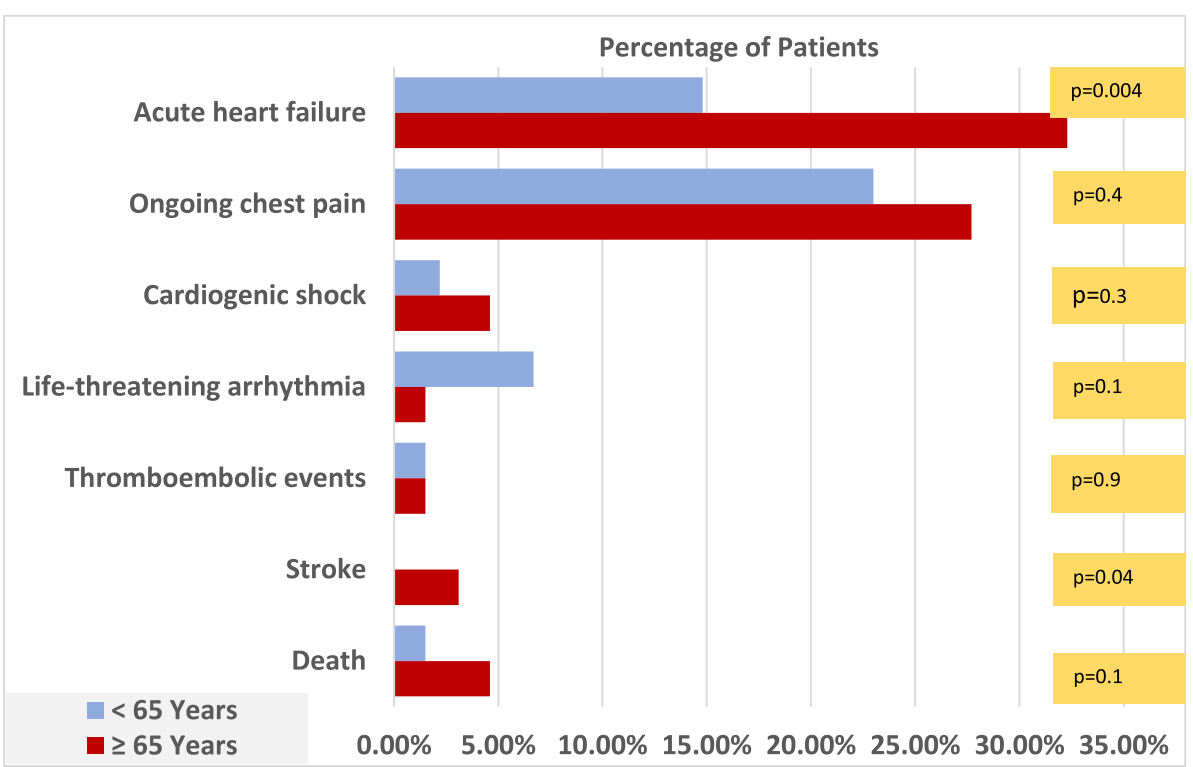

Fig. 5 In-hospital complications in NSTE-ACS patients a according to age category 


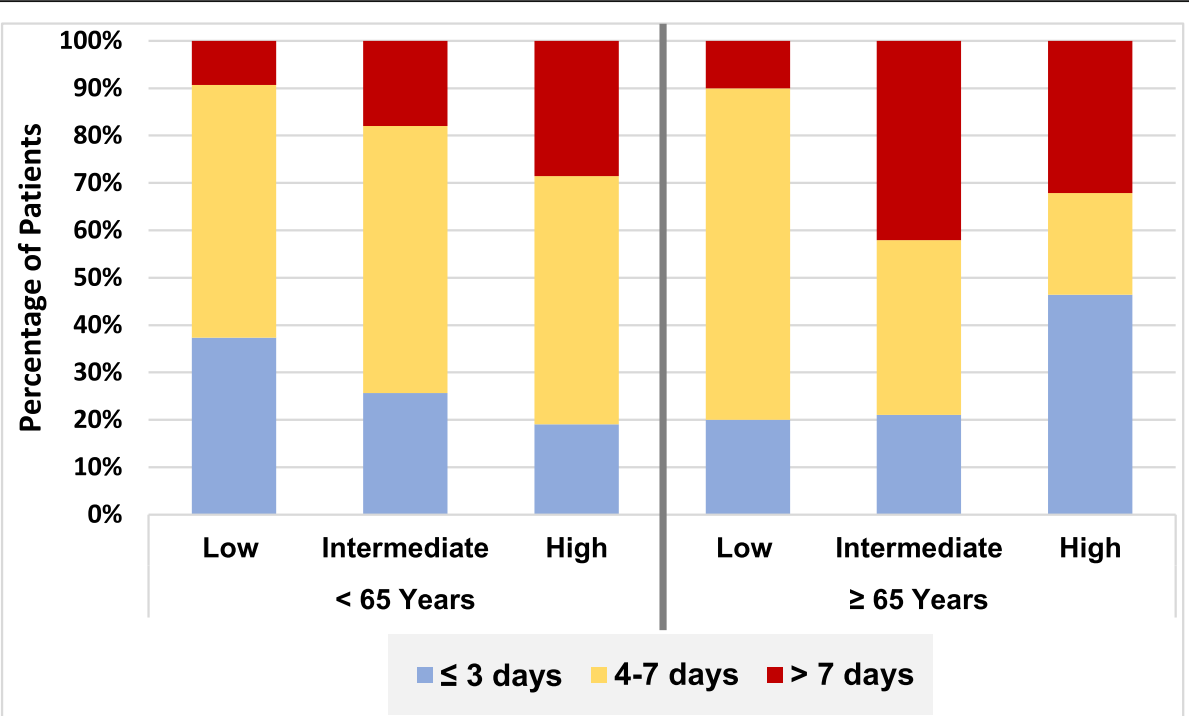

Fig. 6 Hospitalization duration in NSTE-ACS according to age and GRACE risk class. Comparing hospitalization duration between the two age categories according to risk class $p$ value $=0.3$ (low-risk class), 0.6 (intermediate-risk class) and 0.51 (high-risk class)

crucial considering issues like cost-effectiveness, patients' satisfaction, prevention of bed blocking especially in PCIcapable centres, where work flow can be affected remarkably by limited bed capacity which can impact other patients' cardiovascular care and outcomes.

This study provides insight to age differences in the current practice of managing NSTE-ACS which could be due to multiple comorbidities, higher GRACE risk class at presentation and anticipating complications; however, these differences can be overcome by proper risk stratification, adherence to international guidelines in addition to trying to minimize complications like prescribing PPI and using radial approach to decrease bleeding risk as well as GFR estimation and proper assessment of contrast nephropathy risk to minimize it by rehydration and limiting contrast amount. Thus, chronological age alone will not deprive the patient from being managed as indicated because precise risk-benefit assessment will be implemented.

Study limitations are as follows: a larger study population is needed to further validate the statistical results; small sample size was mainly due to absent electronic data base in our healthcare facilities and limited research collaborators. Prognostic impact of using invasive strategy and timing of intervention to achieve most benefit was not assessed in the current study despite being controversial in literature.

\section{Conclusions}

Despite elderly patients with NSTE-ACS presented at higher GRACE risk class and despite the robust guidelines' recommendations, there is an age gap in managing this population in the form of underutilization of invasive strategy depriving them from its prognostic benefit; however, age was not a predictor of invasive strategy underuse on multivariate analysis which suggested that other factors like developing acute heart failure or presence of AF or having lower haemoglobin levels may play a role in determining management strategy. Considering the substantial increase in geriatric population in different societies, it is crucial to bridge the age gap in healthcare system in the setting of ACS management by grasping the attention of decision makers and emphasizing on the adherence of healthcare providers to the guidelines to improve cardiovascular care and outcomes.

\section{Abbreviations \\ NSTE-ACS: Non-ST elevation acute coronary syndromes; GRACE: Global Registry of Acute Coronary Events; ACS: Acute coronary syndromes; AHF: Acute heart failure; AF: Atrial fibrillation; CABG: Coronary artery bypass graft; DM: Diabetes mellitus; GDMT: Guideline-directed medical therapy; HT: Hypertension; MRA: Mineralocorticoid receptor antagonist; $\mathrm{PCl}$ : Percutaneous coronary intervention; PVC: Premature ventricular contraction; AFL: Atrial flutter}

\section{Acknowledgements}

The authors thank the medical staff at Ibn Al-Bitar Cardiac Centre, Baghdad Heart Centre and Nasiriyah Heart Centre for helping the investigators during data collection process.

\section{Authors' contributions}

ZD and HF contributed to conception and design of the study. ZD was responsible for data collection, statistical analysis, data interpretation, and drafting the manuscript. HF did the critical evaluation of the manuscript. Both authors have read and approved the manuscript. 


\section{Availability of data and materials}

The data sets used and/or analysed during the study are available from the corresponding author on reasonable request.

\section{Declarations}

\section{Ethics approval and consent to participate}

The authors assert that all procedures contributing to this work comply with the ethical standards of the relevant national Iraqi guidelines and with the Helsinki Declaration of 1975 , as revised in 2008 , this study is part of a clinical audit on management of NSTE-ACS that has been approved by the ethical and scientific committee in Scientific Council of Cardiology/ Iraqi Board for Medical Specializations. Written informed consent was obtained from all the participants.

\section{Consent for publication}

Not applicable

\section{Competing interests}

The authors declare that they have no competing interests.

\section{Author details}

${ }^{1}$ Al-Kindy College of Medicine, University of Baghdad, Baghdad, Iraq. ${ }^{2}$ Scientific Council of Cardiology, Iraqi Board for Medical Specializations, Baghdad, Iraq.

\section{Received: 23 October 2020 Accepted: 16 March 2021}

Published online: 31 March 2021

\section{References}

1. Yamada T, Chen CC, Murata C, Hirai H, Ojima T, Kondo K, Joseph RH III (2015) Access disparity and health inequality of the elderly: unmet needs and delayed healthcare. Int J Environ Res Public Health 12(2):1745-1772. https://doi.org/10.3390/ijerph120201745

2. Riley WJ (2012) Health disparities: gaps in access, quality and affordability of medical care. Trans Am Clin Climatol Assoc 123:167

3. Kumar S, McDaniel M, Samady H, Forouzandeh F (2020) Contemporary Revascularization dilemmas in older adults. J Am Heart Assoc 9(3):e014477. https://doi.org/10.1161/JAHA.119.014477

4. de Araújo GP, Ferreira J, Aguiar C, Seabra-Gomes R (2005) TIMI, PURSUIT, and GRACE risk scores: sustained prognostic value and interaction with revascularization in NSTE-ACS. Eur Heart J 26(9):865-872. https://doi.org/10.1 093/eurheartj/ehi187

5. Hazra NC, Rudisill C, Gulliford MC (2018) Determinants of health care costs in the senior elderly: age, comorbidity, impairment, or proximity to death? Eur J Health Econ 19(6):831-842. https://doi.org/10.1007/s10198-017-0926-2

6. Roffi M, Patrono C, Collet JP, Mueller C, Valgimigli M et al (2016) 2015 ESC guidelines for the management of acute coronary syndromes in patients presenting without persistent ST segment elevation. Task Force for the Management of Acute Coronary Syndromes in Patients Presenting without Persistent ST-Segment Elevation of the European Society of Cardiology (ESC). Eur Heart J 37:267-315. https://doi.org/10.1093/eurheartj/ehv320

7. Crenshaw JH, Sullivan JM, Ramanathan KB, Mirvis DM, El-Zeky F, Vander ZR (1995) The effect of noncritical coronary artery disease on long-term survival. Am J Med Sci 310(1):7-13. https://doi.org/10.1097/00000441-1 99507000-00005

8. Dakhil Z, Farhan HA (2020) Treatment risk paradox in non ST elevation acute coronary syndromes: Is it a matter of gender gap? J Am Coll Cardiol 75(11 Supplement 1):31. https://doi.org/10.1016/S0735-1097(20)30658-6

9. Dakhil Z, Farhan HA (2020) Off-hours admission of patients with non ST elevation acute coronary syndromes: Does it impact the management strategy? Catheter Cardiovasc Interv 95(52):S1-S229. https://doi.org/10.1002/ ccd.28864

10. Dakhil Z, Farhan HA (2020) Underuse of invasive strategy in elderly patients with non-ST elevation acute coronary syndromes: Is it real? Eur Heart J Suppl 22(Supplement_K):K12. https://doi.org/10.1093/eurheartj/suaa120

11. Bagnall AJ, Goodman SG, Fox KA, Yan RT, Gore JM, Cheema AN, Huynh T, Chauret D, Fitchett DH, Langer A, Yan AT, Canadian Acute Coronary Syndrome Registry I and II Investigators, Canadian Global Registry of Acute Coronary Events (GRACE/GRACE2) Investigators (2009) Influence of age on use of cardiac catheterization and associated outcomes in patients with
non-ST-elevation acute coronary syndromes. Am J Cardiol 103(11):15301536. https://doi.org/10.1016/j.amjcard.2009.01.369

12. Zaman MJ, Stirling S, Shepstone L, Ryding A, Flather M, Bachmann M, Myint PK (2014) The association between older age and receipt of care and outcomes in patients with acute coronary syndromes: a cohort study of the Myocardial Ischaemia National Audit Project (MINAP). Eur Heart J 35(23): 1551-1558. https://doi.org/10.1093/eurheartj/ehu039

13. Orenes-Piñero E, Ruiz-Nodar JM, Esteve-Pastor MA, Quintana-Giner M, Rivera-Caravaca JM, Veliz A, Valdés M, Macías M, Pernias-Escrig V, VicenteIbarra N, Carrillo L, Sandín-Rollán M, Candela E, Lozano T, Marín F (2017) Therapeutic management and one-year outcomes in elderly patients with acute coronary syndrome. Oncotarget. 8(46):80182-80191. https://doi.org/1 0.18632/oncotarget.21260

14. Ayan M, Pothineni NV, Siraj A, Mehta JL (2016) Cardiac drug therapyconsiderations in the elderly. J Geriatr Cardiol 13:992-997. https://doi.org/1 0.11909/j.issn.1671-5411.2016.12.008.

15. Martinez BK, White CM (2019) Pharmacologic considerations in the management of acute coronary syndrome in elderly patients. Expert Opin Pharmacother 20(15):1787-1790. https://doi.org/10.1080/14656566.2019.1639670

16. Alexander KP, Newby LK, Cannon CP, Armstrong PW, Gibler WB, Rich MW, van de Werf F, White HD, Weaver WD, Naylor MD, Gore JM, Krumholz HM, Ohman EM, American Heart Association Council on Clinical Cardiology, Society of Geriatric Cardiology (2007) Acute coronary care in the elderly, part I: non-STsegment-elevation acute coronary syndromes: a scientific statement for healthcare professionals from the American Heart Association Council on Clinical Cardiology: in collaboration with the Society of Geriatric Cardiology. Circulation. 115(19):2549-2569. https://doi.org/10.1161/CIRCULA TIONAHA.107.182615

17. Alexander KP, Newby LK, Armstrong PW, Cannon CP, Gibler WB, Rich MW, van de Werf F, White HD, Weaver WD, Naylor MD, Gore JM, Krumholz HM, Ohman EM, American Heart Association Council on Clinical Cardiology, Society of Geriatric Cardiology (2007) Acute coronary care in the elderly, part II: ST-segment-elevation myocardial infarction: a scientific statement for healthcare professionals from the American Heart Association Council on Clinical Cardiology: in collaboration with the Society of Geriatric Cardiology. Circulation. 115(19):2570-2589. https://doi.org/10.1161/CIRCULATIONAHA.1 07.182616

18. Capodanno D, Angiolillo DJ (2010) Antithrombotic therapy in the elderly. J Am Coll Cardiol 56(21):1683-1692. https://doi.org/10.1016/j.jacc.2010.04.063

19. Collet JP, Thiele H, Barbato E, Barthélémy O, Bauersachs J, Bhatt DL, et al, ESC Scientific Document Group (2020) 2020 ESC Guidelines for the management of acute coronary syndromes in patients presenting without persistent ST-segment elevation. Eur Heart J. https://doi.org/10.1093/eurhea rtj/ehaa575. (Epub ahead of print. PMID: 32860058)

20. O'Gara PT, Kushner FG, Ascheim DD, Casey DE Jr, Chung MK et al (2013) 2013 ACCF/AHA guideline for the management of ST-elevation myocardial infarction: a report of the American College of Cardiology Foundation/ American Heart Association Task Force on Practice Guidelines. J Am Coll Cardiol 61(4):e78-e140. https://doi.org/10.1016/j.jacc.2012.11.019

21. Amsterdam EA, Wenger NK, Brindis RG, Casey DE Jr, Ganiats TG et al (2014) 2014 AHA/ACC guideline for the management of patients with non-STelevation acute coronary syndromes: executive summary: a report of the American College of Cardiology/American Heart Association Task Force on Practice Guidelines. Circulation. 130(25):2354-2394. https://doi.org/10.1161/ CIR.0000000000000133

22. Carroll KA, Early NK, Tsu LV (2015) Managing acute coronary syndromes in the elderly. Consult Pharm 30(5):265-282. https://doi.org/10.4140/TCP.n.2015.265

23. Del Sindaco D, Tinti MD, Monzo L, Pulignano G (2010) Clinical and economic aspects of the use of nebivolol in the treatment of elderly patients with heart failure. Clin Interv Aging 5:381-393. https://doi.org/1 $0.2147 /$ CIA.S4482

24. Buber J, Goldenberg I, Kimron L, Guetta V (2013) One-year outcome following coronary angiography in elderly patients with non-ST elevation myocardial infarction: real-world data from the Acute Coronary Syndromes Israeli Survey (ACSIS). Coron Artery Dis 24:102-109 33

25. Di Bari M, Balzi D, Fracchia S, Barchielli A, Orso F et al (2014) Decreased usage and increased effectiveness of percutaneous coronary intervention in complex older patients with acute coronary syndromes. Heart. 100(19): 1537-1542. https://doi.org/10.1136/heartjnl-2013-305445

26. Devlin G, Gore JM, Elliott J, Wijesinghe N, Eagle KA, Avezum A, Huang W, Brieger D, GRACE Investigators (2008) Management and 6-month outcomes 
in elderly and very elderly patients with high-risk non-ST-elevation acute coronary syndromes: The Global Registry of Acute Coronary Events. Eur Heart J 29(10):1275-1282. https://doi.org/10.1093/eurheartj/ehn124

27. De Servi S, Cavallini C, Dellavalle A, Santoro GM, Bonizzoni E et al (2004) ROSAI-2 Investigators. Non-ST-elevation acute coronary syndrome in the elderly: treatment strategies and 30-day outcome. Am Heart J 147(5):830836. https://doi.org/10.1016/j.ahj.2003.12.016

28. Sanchis J, Núñez E, Barrabés JA, Marín F, Consuegra-Sánchez L, Ventura $S$, Valero E, Roqué M, Bayés-Genís A, del Blanco BG, Dégano I, Núñez J (2016) Randomized comparison between the invasive and conservative strategies in comorbid elderly patients with non-ST elevation myocardial infarction. Eur J Intern Med 35:89-94. https://doi.org/10.1016/j.ejim.2016.07.003

29. Savonitto S, Cavallini C, Petronio AS, Murena E, Antonicelli R, Sacco A, Steffenino G, Bonechi F, Mossuti E, Manari A, Tolaro S, Toso A, Daniotti A, Piscione F, Morici N, Cesana BM, Jori MC, de Servi S, Italian Elderly ACS Trial Investigators (2012) Early aggressive versus initially conservative treatment in elderly patients with non-ST-segment elevation acute coronary syndrome: a randomized controlled trial. JACC Cardiovasc Interv 5(9):906916. https://doi.org/10.1016/j.jcin.2012.06.008

30. Tegn N, Abdelnoor M, Aaberge L, Endresen K, Skårdal R et al (2016) Invasive versus conservative strategy in patients aged 80 years or older with non-STelevation myocardial infarction or unstable angina pectoris (After Eighty study): an open-label randomised controlled trial. Lancet. 387(10023):10571065. https://doi.org/10.1016/S0140-6736(15)01166-6

31. Bach RG, Cannon CP, Weintraub WS, DiBattiste PM, Demopoulos LA et al (2004) The effect of routine, early invasive management on outcome for elderly patients with non-ST-segment elevation acute coronary syndromes. Ann Intern Med 141(3):186-195. https://doi.org/10.7326/0003-4819-141-3-2 00408030-00007

32. Angeli F, Verdecchia P, Savonitto S, Morici N, De Servi S, Cavallini C (2014) Early invasive versus selectively invasive strategy in patients with non-STsegment elevation acute coronary syndrome: impact of age. Catheter Cardiovasc Interv 83(5):686-701. https://doi.org/10.1002/ccd.25307

33. Garg A, Garg L, Agarwal M, Rout A, Raheja H, Agrawal S, Rao SV, Cohen M (2018) Routine invasive versus selective invasive strategy in elderly patients older than 75 years with non-ST-segment elevation acute coronary syndrome: a systematic review and meta-analysis. Mayo Clin Proc 93(4):436444. https://doi.org/10.1016/j.mayocp.2017.11.022

34. Reaño JD, Shiu LA, Miralles KV, Dimalala MG, Pestaño NS et al (2020) A systematic review and meta-analysis on the effectiveness of an invasive strategy compared to a conservative approach in patients > 65 years old with non-ST elevation acute coronary syndrome. PLoS One 15(2):e0229491. https://doi.org/10.1371/journal.pone.0229491

35. Kvakkestad KM, Gran JM, Eritsland J, Hansen CH, Fossum E, Andersen G $\varnothing$, Halvorsen S (2019) Long-term survival after invasive or conservative strategy in elderly patients with non-ST-elevation myocardial jnfarction: a prospective cohort study. Cardiology. 144(3-4):79-89. https://doi.org/10.11 59/000503442

36. Badings EA, Hermanides RS, Van Der Sluis A, Dambrink JH, Gosselink AT et al (2019) Use, timing and outcome of coronary angiography in patients with high-risk non-ST-segment elevation acute coronary syndrome in daily clinical practice: insights from a 'real world' prospective registry. Neth Hear J 27(2):73-80. https://doi.org/10.1007/s12471-018-1212-3

37. Afzal R, Chrolavicius S, Jolly SS, Widimsky P, Avezum A et al (2009) Early versus delayed invasive intervention in acute coronary syndromes. N Engl J Med 360:2165-2175. https://doi.org/10.1056/nejmoa0807986

38. Costantini C, Stuckey T, Tcheng JE, Mehran R, Lansky AJ, Grines CL, Stone GW (2010) Impact of delay to angioplasty in patients with acute coronary syndromes undergoing invasive management: analysis from the ACUITY (Acute Catheterization and Urgent Intervention Triage strategY) trial. J Am Coll Cardiol 55:1416-1424. https://doi.org/10.1016/j.jacc.2009.11.063

39. Rosengren A, Wallentin L, Simoons M, Gitt AK, Behar S, Battler A, Hasdai D (2006) Age, clinical presentation, and outcome of acute coronary syndromes in the Euroheart acute coronary syndrome survey. Eur Heart J 27(7):789-795. https://doi.org/10.1093/eurheartj/ehi774

40. Mirghani $\mathrm{HO}$ (2016) Age related differences in acute coronary syndrome presentation and in hospital outcomes: a cross-sectional comparative study. Pan Afr Med J 24. https://doi.org/10.11604/pamj.2016.24.337.8711

41. Su PH, Chen PY, Lee SY, How CK, Chien DK, Chang WH (2019) Comparison of clinical presentations and outcomes between adult and elderly acute myocardial infarction patients in emergency department. Heal Technol 3:7. https://doi.org/10.21037/ht.2019.08.01

42. Węgiel M, Dziewierz A, Wojtasik-Bakalarz J, Sorysz D, Surdacki A, Bartuś S, Dudek D, Rakowski T (2018) Hospitalization length after myocardial infarction: risk-assessment-based time of hospital discharge vs real life practice. J Clin Med 7(12):564. https://doi.org/10.3390/jcm7120564

43. Laurencet ME, Girardin F, Rigamonti F, Bevand A, Meyer P, Carballo D, et al (2016) Early Discharge in Low-Risk Patients Hospitalized for Acute Coronary Syndromes: Feasibility, Safety and Reasons for Prolonged Length of Stay. PLoS One. 11(8):e0161493. https://doi.org/10.1371/journal.pone.0161493

44. Ibanez B, James S, Agewall S, Antunes MJ, Bucciarelli-Ducci C et al (2017) ESC guidelines for the management of acute myocardial infarction in patients presenting with ST-segment elevation: The Task Force for the management of acute myocardial infarction in patients presenting with STsegment elevation of the European Society of Cardiology (ESC). Eur Heart J 2018(39):119-177. https://doi.org/10.1093/eurheartj/eh×393

\section{Publisher's Note}

Springer Nature remains neutral with regard to jurisdictional claims in published maps and institutional affiliations.

\section{Submit your manuscript to a SpringerOpen ${ }^{\circ}$ journal and benefit from:}

- Convenient online submission

- Rigorous peer review

- Open access: articles freely available online

High visibility within the field

- Retaining the copyright to your article

Submit your next manuscript at $\boldsymbol{\nabla}$ springeropen.com 